\section{Adjustment, Estimation, and Uses of Equilibrium Reaction Constants in Aqueous Solution}

IUPAC project \#2000-003-1-500 has produced a suite of programs to study quantitatively the influence of ionic strength changes on equilibrium constants, with particular emphasis on using specific interaction theory (SIT). This new project is intended to extend this previous work in the following ways:

- apply Pitzer parameters in a more general way to equilibria of environmental and industrial importance, with particular importance given to seawater and mixed fluids

- extend and improve a database of published SITand Pitzer-related parameters that can be accessed by all relevant programs in the suite and may be edited by the user

- extend the package to cover other environmentally important gases such as air, $\mathrm{H}_{2}, \mathrm{~N}_{2}$, rare gases, $\mathrm{N}_{2} \mathrm{O}$, $\mathrm{CH}_{4}$, and other paraffins (currently the package allows calculations on the effects of dissolved $\mathrm{O}_{2}$ )

- explore and test ways of displaying graphically the relationship between ionic strength and temperature with activity coefficients $\lg \mathrm{K}^{0}$ and $\lg \mathrm{K}$

- explore and test ways of displaying graphically the effects of errors on the relationships studied above

- calculate and demonstrate graphically the effect of errors on species distribution curves

- provide the outline of a database of reliable literature values of the dependence of stability constants on temperature

The current version of the suite of programs (Aq_solutions.zip, about $7 \mathrm{MB}$ ) is available from project \#2000-003-1-500.

For more information, contact Task Group Chairman Igor Sukhno <sukhno@chem.kubsu.ru〉.

Siif www.iupac.org/projects/2006/2006-010-1-500.html

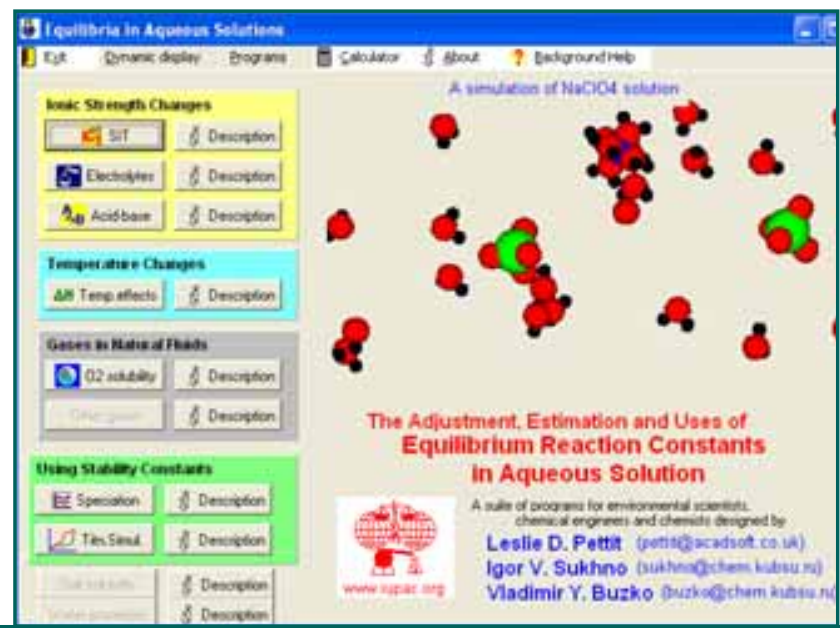

\section{Design of Polymer Education Material for French-Speaking Countries}

The need for a standard in polymer education has been recognized by French-speaking academics in both emerging and developed countries. The aim of this project is to set up a basic course at the undergraduate level for French-speaking countries that takes into account their local contexts. This course will be illustrated with attractive materials (e.g., a database, teaching documents, videos) provided by partners of the project and will be made available free of charge to the education community.

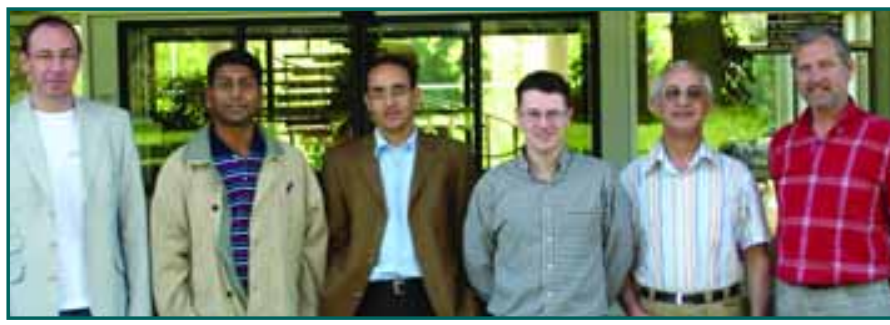

Task group participants (from left): P. Degee (Belgium), D. Jhurry (Mauritius), H. Kaddami (Morocco), A. Soldera (Canada), M. Popa (Romania), and G. Froyer (France).

The first meeting of the project was held at the Institut des Matériaux Jean Rouxel in Nantes, France, on 9-10 June 2006, under the sponsorship of the Université de Nantes. At this workshop, participants further improved the standard program that has been proposed via e-mail exchanges during the previous year. Attendees worked on existing available materials such as CDs and videos, rating their quality, appearance, and scientific consistency. This exercise gave them a better picture of how the polymer course should be mounted and how to make it as attractive as possible for the undergraduate students.

The group decided to share the task of mounting the polymer course among five subgroups, each one having responsibility for designing a specific part of the agreed-upon standard course. A follow-up meeting is planned for mid-2007 to validate the work done by the different subgroups.

For more information, contact Task Group Chairman Gerard Frover <gerard.frover@cnrs-imn.fr>.

Siii. www.iupac.org/projects/2004/2004-037-1-400.html 